\section{El valor de la imagen en la adaptación de cuentos clásicos. Vigencia, valores e impacto en el imaginario colectivo}

The Value of the Image in Adapting Classic Fairytales. Validity, values and impact in the collective imagination

Vicente Perpiñá Giner

Palabras clave: Cuento Ficción, Lenguaje, Axiología, llustración Key words: Tale, Fiction Language, Axiological, Illustration
Para buscar las raíces de los cuentos de hadas debemos indagar en el proceso histórico de los mismos. Estudiar su valor axiológico, narrativo, contextual y el proceso de codificación. Indagación que nos llevará a su sustento en las leyendas y mitos más antiguos basados el afán humano de explicar la realidad y servirse de los recursos retóricos del lenguaje y la comunicay servirse de los recursos retoricos del lenguaje y la comunicación, que habla asimismo de nuestra evolución como colectivo.

If we want to find the roots of the fairy tales, we should delve into their historical process. We should study all their axiological, narrative and context values, and also their encoding process. Inquiry that will lead us to their livelihood in legends and ancient myths based in human desire to explain reality and the rhetorical use of language and communication, which also speaks of our evolution as a collective.
Érase una vez... Introducción

Si mencionamos a Pinocho o Caperucita, inmediatamente nos figuraremos una imagen mental de ellos. Incluso casi automáticamente surgirá en nosotros la conciencia en forma de Pepito Grillo que nos advertirá de los peligros morales de la mentira, o el miedo a adentrarnos en el bosque en el que habita el Lobo Feroz. Son personajes protagonistas de cuentos tradicionales, historias que nuestros padres nos han contado alguna vez, que hemos leído en libros, visto en el cine, etc. Casi podríamos afirmar que nos han acompañado desde que tenemos uso de razón a los nacidos en el siglo XX. Más concretamente podríamos decir que llevan incrustados en el imaginario colectivo de la sociedad occidental desde hace unos cientos de años, pero esta afirmación tampoco sería categórica, porque aún se puede ir más atrás en el tiempo para encontrar su raíz. ¿A qué se debe? ¿Quién le ha contado estas historias a quienes nos las cuentan a nosotros? ¿Quiénes los han puesto ahí?

Es aquí donde surge la pregunta, si se quiere, más esencial: ¿De dónde vienen los cuentos?

Será manido e incluso osado hablar de un bisonte garabateado en la pared de una caverna por un hombre primitivo, pero es una imagen indispensable para hacer comprensible el punto de partida del viaje que queremos relatar, que no es sino un cuento más, quizá el más largo de todos.

Para indagar sobre la historia del relato popular debemos trasladarnos antes del nacimiento de la literatura, quizá antes de la aparición de la escritura codificada, a cuando un dibujo simple con un palo sobre la arena nos permitía comunicarnos. Pues como se aventuró a dilucidar Vladimir Propp en Las raíces históricas del cuento ${ }^{1}$, éstos son una

extensión de mitos más antiguos. Constructos primitivos que nacieron con nosotros, como especie, desde que aprendimos a comunicarnos y organizarnos, y al tiempo que avanza nuestra historia, avanzan con nosotros transformándose, generando y rechazando creencias, siendo usados en muchas ocasiones para explicar a través de un código lo que nos resulta inexplicable

Del mismo modo que se construyeron textos que fundamentaron las religiones o los códigos morales se codificaron estas historias, los cuentos. Varios autores son los responsables de esta empresa. Destacaremos a Charles Perrault o los Hermanos Grimm, en su vocación de recolectores de leyendas o a otros como Hans Christian Andersen que más allá de partir de la tradición popular, comenzaron a crear sus propias historias vinculadas con su propia experiencia.

Ahora bien, como la sociedad, dichas narraciones han sufrido un proceso histórico y evolutivo, en cuanto al qué contar, el cómo contarlo y el para qué y quién contarlo. En un principio fueron ideados como relatos para cualquier tipo de público, pero desde su factor pedagógico y 
sujetos a adaptaciones contextuales, se han dirigido a un público infantil, siendo éste un factor determinante. No son meros embustes para entretener a los niños y también (porque tan importante es el destinatario como quien elabora y hace uso del medio), sino concepciones retóricas del mundo circundante, sujetas y deudoras a partes iguales de la experiencia, la realidad, la razón y la imaginación del ser humano.

En el artículo El lado oscuro de los cuentos de los Hermanos Grimm² $^{2}$ el Dr. Miguel Salmerón Infante dice:

«Puede ser que (...) cualquier pueblo y cualquiera de los sujetos que lo componen en relación con el sujeto colectivo, no sea tan sano, ni tan encomiable como quiere verse a sí mismo. (...) Probablemente no ignoraban esto los Grimm cuando en el prólogo a Las leyendas alemanas, diferenciaban la leyenda y el cuento, haciendo, eso sí, una distinción previa de ambos con respecto a la historia. Parafraseando a Aristóteles podríamos decir que la historia es lo que pasó y el cuento y la leyenda lo que puede pasar. E incluso cuento y leyenda discurren en un ámbito de lo que puede pasar, de lo posible, exclusivamente sostenido por lo ficticio, pues tanto en leyenda como en cuento se mezcla lo verosímil e inverosímil. Por otra parte, cuento y leyenda tienen destinatarios diferentes. Mientras que el pueblo cree ly ha de creer) en la verdad de las leyendas, los niños creen en la verdad de los cuentos.."

Si bien no podemos otorgarles un origen certero sí podemos saber que fueron recopilados, es decir transcritos, adaptados, construidos si se quiere, mediante la comunicación de boca en boca y el paso del tiempo. Retuvieron su esencia o quizá la transformaron en una suerte de mutación indiscriminada sujeta al contexto en que nacieron o se desarrollaron. Hasta que una serie de autores, a partir de estos relatos primitivos procesados por la condición humana usaron la palabra escrita, en tanto que conjunto de signos gráficos para codificarlos. Este mero proceso de codificación, ya transforma a los cuentos en ficciones que, sirviéndose de las posibilidades que éstas ofrecen, se constituyen en productos para conocer, estructura y comunicar valores axiológicos humanos.

Tratamos, en este comunicado, de analizar el papel y el impacto social de la ilustración como lenguaje en la adaptación literaria. Desde las primeras imágenes que se usaron para acercar los relatos al público, a los encargos para ediciones de los mismos o a las producciones de cine de animación, las técnicas utilizadas y el proceso histórico que sufren, sujetos a su morfología.

Así pues también podemos aventurarnos a decir que los relatos populares retoman mitos antiguos, que quizá nos han acompañado siempre hasta incluso antes de que tuviésemos codificado el lenguaje escrito. Ya era entonces cuando gráficamente lo representábamos en las lúgubres paredes de una caverna.

Haremos a continuación un estudio pormenorizado de una serie de autores, relatos, personajes y recursos de representación. Escogidos todos ellos por afinidad personal y por creerlos convenientes para servir 2 SALMERÓN INFANTE, MIGUEL: los Hermanos Grimm". Herejía y belleza, 1 (2012), pp.8-21. 3 lbidem, p. 10. de ejemplo a pequeña escala de la importancia de la realidad, del arte literario y el gráfico en el proceso histórico del desarrollo del cuento.
Las adaptaciones literarias. Un punto de inflexión en la historia.

La tradición oral del acervo popular occidental, incluso las líneas invisibles que unen comunidades ajenas, como pueblos lejanos sin contacto aparente entre sí, poseen mitos similares tanto en su morfología como en su necesidad. La necesidad de tratar de explicar lo que no se comprende para comprenderlo, sirviéndose de aquello que conocemos, derivar en la metaforización, en el uso de elementos de la naturaleza, animales, símiles codificados de nosotros mismos para tanto distanciarnos como acercarnos al relato.

Ya en la tradición medieval se recopilan cuentos de hadas, como en los Cuentos de Canterbury de Geoffrey Chaucer, así como la figura de trovador relataba cuentos y leyendas, quizá más vinculados a pequeñas comunidades o a su propia persona. Más tarde siguió la tradición literaria de coleccionar cuentos en las tradiciones italiana o china, pero dónde más popular se hizo fue en Francia entre las clases más altas.

Destacaremos como ilustre emprendedor de esta recopilación y codificación literaria a Charles Perrault (París, 1628-1703), a quien se le atribuye la primera escritura de cuentos tan reconocidos como Caperucita Roja o El Gato con Botas y que adecuó a su forma actual las versiones de La Bella Durmiente y Cenicienta. Todos ellos recopilados en Les Contes de ma mère l'Oye (Los cuentos de mamá oca). Si bien su trabajo fue el de reescribir y moderar la crudeza de ciertas versiones orales que dejaba patente su nuevo hábitat, la forma escrita.

Los hermanos de origen alemán Jacob Grimm (Hanau, 1785 - Berlín, 1863) y Wilhelm Grimm (24 de febrero de 1786, Hanau, 1786 - Berlín, 1859) fueron reconocidos tanto por su Diccionario alemán, la Gramática Alemana, las Leyendas alemanas, la Mitología alemana como por Cuentos de la infancia y del hogar. Trataron de mantener en su recopilación de los cuentos orales la trama, los personajes y el estilo. Aunque con tal de popularizarse y asegurar grandes ventas realizarían adaptaciones posteriores más "aceptables" para la sociedad del momento. Beligerantes respecto al origen y la pureza de los cuentos, descartando aquellos derivados de las recopilaciones hechas por ejemplo por Perrault, salvo el caso de La Bella durmiente, figura (Brunilda) que según Jakob Grimm pertenecía al folclore alemán. Este hecho promulgó la necesidad, entre ciertos folcloristas coetáneos, de conservar la forma auténtica y no "contaminada" por el medio literario. Pero es imposible, como bien hemos explicado hallar la raíz primigenia exacta de los cuentos, pues ya el mero trasvase oral permitía a cada cuentacuentos alterar la historia según su propio interés.

Así pues, Roman Gubern, en Máscaras de la ficción nos advierte:

"Pero aquellos signos gráficos, convertidos en atributos, son el resultado de la construcción mental previa de un autor, que el lector hace también suya en el curso de la lectura, pues el sistema simbólico del texto desemboca en el logomorfismo que otorga vida imaginaria al personaje, al hacer que el lector proyecte un haz de motivaciones psicológicas coherentes sobre su constructo literario. (...) el personaje como entidad imaginaria, a veces tan sólida y espesa como el mármol y capaz de transmutarse incluso en ocasiones en un verdadero delirio colectivo, pues es lo que suscita las identificaciones y proyecciones de sus lectores.
4 GUBERN, ROMAN: Mascaras de 2002. 5 lbídem, p. 9. 
Es el autor quien propone y dispone estos constructos, tan fantasiosos como verosímiles, al colectivo, exponiéndolos a través de los medios de difusión, y son los receptores de este mensaje quienes sin darse cuenta adoptan y conviven con las peripecias, desdichas, triunfos y aventuras que viven sus personajes, que se erigen en mitos aferrándose al tejido del imaginario del colectivo social. Siendo ficciones proyectadas en la realidad y por lo tanto funcionales como reflejo de la misma para el uso que el individuo haga de ellas, siendo una suerte de conciencia sujeta al contexto que habita.

\section{El papel de la ilustración.}

El cuento es un claro ejemplo de guía moral, de conducta y de entretenimiento, tanto el relato escrito como en el relato contado con imágenes

Como bien apuntábamos anteriormente, uno de los códigos en tanto en cuanto que lenguaje de difusión de los cuentos, es el gráfico. La ilustración juega un papel fundamental en la historia y la morfologia de dichas narraciones populares, siendo no tan sólo un acompañamiento, sino una estrategia de adaptación deliberada, que dota de un nuevo aspecto, que acerca y hace legible de otro modo su función y cometido, y que nos ha proporcionado los arquetipos del imaginario colectivo a los que hacer referencia. Siendo un medio indispensable para su difusión, desde la imagen estática a la imagen-movimiento, un método de permanencia, de vigencia en constante revisión, en una suerte de esencia mutable de aquel cometido por y para el que nacieron. Mostrar, como ya se hacía en las cavernas, de forma visual al mito. Poner en imagen, golpear a la vista y a la psique, sin necesidad de hacer trabajar a nuestra imaginación, tener delante de nosotros una imagen que nos inspire distintas sensaciones, un reportaje gráfico de lo agradable, lo fantástico, lo bello o lo tenebroso.

Estas estrategias de representación y comunicación han sido cada vez más, y más capaces, desde la era industrial hasta nuestros días de la era de la velocidad y globalización, hasta poder, fruto del bombardeo indiscriminado a través de los medios, llegar al máximo público, traspasar fronteras, barreras físicas y geográficas e incluso culturales, contaminándose y acentuando lo cambiante de su esencia, aunque suene incongruente.

Destacaremos a Gustave Doré (Estrasburgo, Francia 1832 - París, Francia, 1883), artista polifacético, pero reconocido grabador e ilustrador. Figura esencial en la construcción gráfica de mitos. De estilo realista no exento de caricaturizar o exagerar la morfología del personaje para adecuarlo tanto a un contexto como a la acción que realiza y que economiza trazos tanto como los requiere en otros momentos según qué contar. Debemos realzar su figura de documentalista y reportero gráfico en obras junto a Charles Davillier como Viaje por España, su Quijote sus obras que mostraron la parte más pobre y triste de Londres, con las que se cebó la crítica al no hacer una alegoría de las bondades de la ciudad, que lo muestra como un captador de realidades, lo que hace que veamos verosimilitud en su representación de personajes.

Como bien hemos dicho antes, el cuento se ha dirigido generalmente a un público infantil, así pues, al tiempo que la sociedad cambia, también lo hace la visión de qué estímulos y qué códigos está dispuesto a recibir y asimilar un niño. De tal manera, del mismo modo que el lenguaje escrito requiere de una adaptación respecto a las capacidades del infante, a la par la evolución gráfica de los relatos para niños adopta también otro carácter. Del realismo de las primeras ilustraciones a la sencillez, la dulzura y el antropomorfismo. Economía de línea sujeta al contexto pero también a los requerimientos técnicos dada la dificultad de técnicas como el cine de animación, pero también con una intención de integrar y empatizar con el personaje, que se torna en ocasiones más bien un pobre tarugo que una feroz y voraz bestia.

Tomaremos como ejemplo al Lobo Feroz de Caperucita. La representación salvaje de un miedo, de lo desconocido, una figura retórica de contraposición a la seguridad, lo que se nos escapa, lo que no podemos controlar y se abalanza sobre nosotros. Fijémonos en la versión disfrazado de abuelita que grabó Doré para la edición de 1883 de los cuentos de Perrault (fig. 1) y la versión animada de Merhen Okoku para la Toei Animation japonesa de 1995 (fig.2).

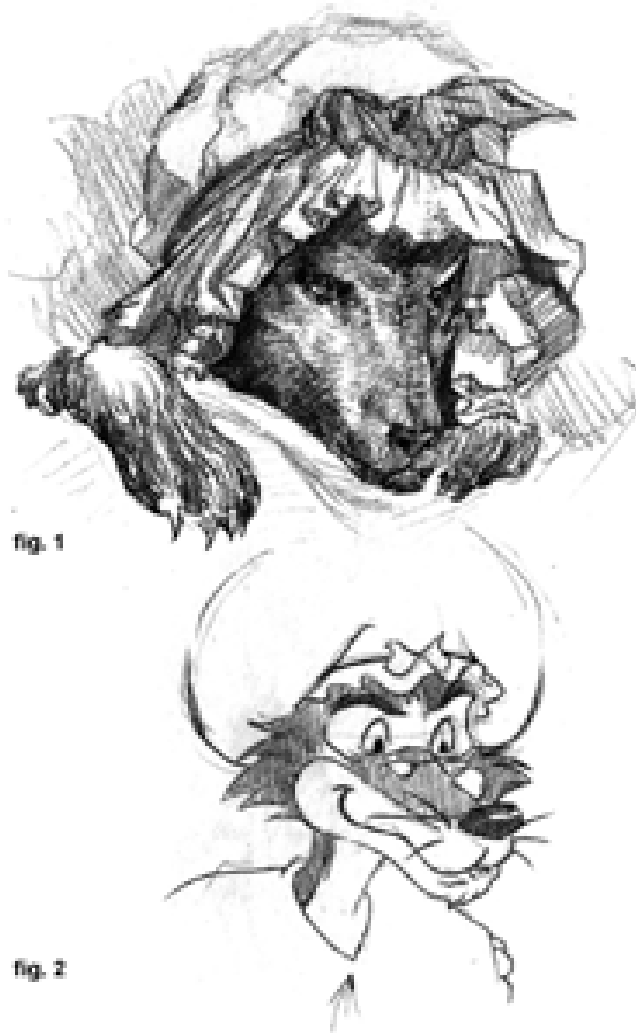

Figuras 1 y 2. Estudio del Lobo Feroz de Dore y de la versión Giner 2015 


\section{El Barón de Münchhausen. Un ejemplo de la evolución morfológi-}

\section{ca, histórica y de representación del mito a pequeña escala.}

Personaje fantástico, intrépido aventurero abanderado de la fantasía, con casaca roja, sombrero de campaña con pluma, de soberana nariz, atractivo bigote, espada y rocín. Quien en el final de la adaptación cinematográfica de sus aventuras por Terry Gilliam en 1988, guiando al pueblo blandiendo la espada de la imaginación solicitaba abrir las puertas de la ciudad para ver que el asedio del Gran Turco había cesado, que la fantasía abandonada de la razón y sus contingentes maravillas habían logrado vencer a una guerra liderada por la razón, premisa que aparentemente puede ser descabellada, pero más extraño puede sonar que un conflicto destructivo atienda a la virtud de coherencia del ser humano. Quizá deberíamos colarnos a través de la portalada, entre piernas, encajes y enaguas, a la altura de un gato curioso, e ir en contra del caudal del río de gente para transportarnos al inicio de esta historia, el punto de partida del mito y quizá lo más asombroso de todo, que existió de verdad.

Karl Friedrich Hieronymus, barón von Münchhausen (1720-1797) fue paje del duque de Brunswick-Luneburgo Antonio Ulrico II, con quien viajó a Rusia y en principio fue nombrado corneta de la caballería. Más tarde ascendió a teniente participando en dos enfrentamientos contra el Imperio Otomano en 1740 y 1741, año en el que Antonio-Ulrico, ya generalísimo fue encarcelado. Permaneció en el ejército ruso, del que fue nombrado capitán en 1950. Tras retirarse, residió con su esposa Jacobine Von Dunten en Bodenwerder, siendo un honorable y reputado hombre de negocios. A partir de la década de 1780, empezó a crecer su fama de embustero y cuentacuentos, por los exagerados relatos sobre sus experiencias en las campañas militares que ofrecía a sus invitados, acompañado siempre, dicen las malas lenguas, con una copa de vino. Tras el fallecimiento de su esposa en 1790, Münchhausen contrajo matrimonio una vez más en 1794 con Bernadine von Brunn, pero éste fue tortuoso y terminó en un sonado divorcio. Pese a que von Brunn tuvo una hija en 1795, no fue reconocida oficialmente como hija del barón, y éste murió sin descendencia natural en 1797.

En psicología, el Síndrome de Munchausen es aquél en el que el paciente finge padecer los síntomas de diversas enfermedades para recibir la atención de los demás.

Más controvertido aún que su propia vida es el proceso de adaptación literario de sus aventuras.

El personaje real tenía fama de relatar sus hazañas más allá de los preceptos reales, pero no podemos atestiguar qué hay de cierto en lo que contó ni tan siquiera en el hecho de que lo contara. Nos encontramos ante un perfecto ejemplo a pequeña escala del proceso histórico que puede sufrir la forja de un mito. Desde un punto de partida de la hipotética exageración en pos de entretener a sus espectadores, hasta la adaptación literaria de dichas historias, pasadas por el filtro creativo y de ficción que aporta un autor ajeno a ellas, y las consiguientes reinterpretaciones gráficas, cinematográficas, teatrales, etc., hasta el calado en nuestro imaginario erigido en esa guisa de fantasma permanentemente presente, patrón ejemplar de nuestra conducta.

Suele atribuirse la autoría de la versión escrita a Rudolf Erich Raspé, persona que merecería artículo aparte. En 1785 traduce del alemán al inglés e introduce nuevas historias a la octava parte del Vade Mecum für lustige Leute, de August Mylius de 1781, configurando lo que sería Baron Münchhausen's Narrative of his Marvellous Travels and Campaigns in Russia, a la que en 1786 se le añadieron las aventuras marinas y que fue el texto que alimentó la más popular de las versiones, la de Gottfried August Bürger. Miguel Sáenz en el prólogo de la versión española del ibro editada por Alianza en $1982^{6}$ nos dice:

"Sea como fuere, corresponde a Gottfried August Bürger (1747-1794) la gloria de haber dado al Münchhausen (aunque también anónimamente) su forma más perfecta y definitiva. Bürger tradujo a Raspé (como tradujo el Macbeth) por razones puramente crematísticas, y hasta después de su muerte no se descubrió su paternidad Pero, aunque él mismo se considerase sólo un traductor $y$ adaptador purantar,

Y sigue:

«Muchas de las mejores historias del libro lla cabalgada sobre la bala de cañón, la caza de patos con tocino, la coleta salvadora, el brazo golpeador) son suyas, pero, sobre todo, supo dar al Münchhausen — con una traducción "que no se aferraba temerosamente a las palabras" - un lenguaje vivo, directo y enormemente expresivo.."

Así pues, nos encontramos ante que la adaptación "definitiva" es la traducción y adaptación de una primera traducción de una adaptación de un rumor, aunque suene enrevesado.

Ahondando en la adaptación plástica, debemos incidir en la gran cantidad de obra gráfica derivada de las aventuras del barón, desde las versiones de los británicos Thomas Rowlandson (1756-1827) y George Cruikshank (1792-1878), pero debemos rendirnos una vez más ante Gustave Doré, de quien Sáenz nos dice:

"Sin embargo, todas me parecen inferiores a los espléndidos grabados de Doré sobre la traduccion hecha en 1853 por Teophile Gautier): habiendolos visto alguna vez, resulta casi imposible imaginarse a Münchhausen de otro modo.» ${ }^{9}$

El personaje traspasará las páginas de papel para introducirse en el celuloide de la mano de, primero, los pioneros del cine Emile Cohl en Les Adventures du Baron du Crac (ca. 1908), y Georges Meliés en Les Hallucinations du baron de Münchausen (1911) a modo de cortometraje mudo, a quien ya habían influido las aventuras del barón para su célebre Le Voyage dans la Lune (1902). La descomunal, más por su despliegue técnico de los estudios alemanes UFA, Münchhausen de Hans Albers y escrita por Joseph von Baky (1943). Mención aparte
( chhausen, Madrid, Barón de Mún-

9 lbídem, p. 9. 


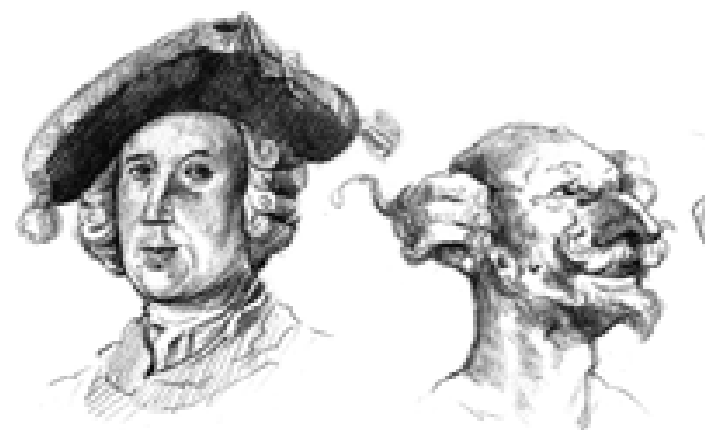

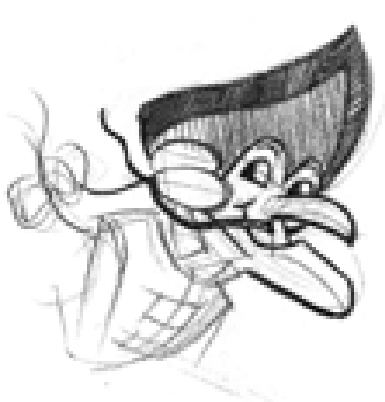

25

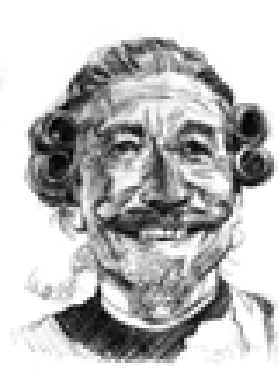

s.t.
Figuras $3,4,5$ y 6 . Estudio de la evolución de la figura del Barón de Münchhausen a partir del único retrato que se conserva, la caricaturización de Doré, la versión animada de 1979 y la caracterización de Jo Neville para la película de 1988 merecen las encomiables y maravillosas adaptaciones del cine de animación experimental mezclando imagen real del checho Karel Zeman, El barón fantástico (Baron Práśil) (1961) o el cortometraje de animación con muñecos Las aventuras del Barón de Münchhausen, dirigido por Anatóliy Karánovich (1967). Destacando también la ya mencionada relectura cinematográfica de Terry Gilliam de los años 80, entre otras.

A continuación, hacemos acopio de un estudio de cuatro de las distintas versiones del personaje. En la figura 1, observamos una interpretación del retrato en uniforme de coracero ruso del auténtico barón. En la figura 2, nos encontramos ante un estudio de la caricatura elaborada por Doré, que dotará al iqual que hizo Bürger en la literatura de ese toque especial y definitorio por el que siempre recordaremos al personaje, siendo ésta la versión a la que cualquier adaptación posterior deberá sentirse deudora. Vemos como el ilustrador francés hizo gala de la economía de trazo tornando la imagen más bien en una caracterización paródica, estilo con el que acometerá la mayoría de los grabados que ilustran el libro, ágiles, sencillos, que parecen estar en movimiento y que se adecuan a las escenas que se pretende relatar. En otras planchas hará gala de su estilo más realista y elaborado. La caracterización que se buscó para la producción animada de Jean Image (1979) (fig. 3), es claramente deudora de la impronta de Doré, nótese en la coleta, en el gesto y la morfología de la nariz en conjunción con la mandíbula y que como antes hemos matizado, recurre a la simplificación gráfica por tratarse de una película para niños y por las necesidades técnicas de la animación. Otro claro ejemplo de esta influencia es la caracterización del actor John Neville para la adaptación cinematográfica de 1988 (fig. 4).

Hemos visto con Münchhausen cómo se forja un mito, desde que parte de una entidad real, de lo que se le atribuye a ésta por el colectivo social que lo circunda, convirtiéndolo primero en una leyenda a pequeña escala, cómo trasciende y se transforma adaptándose a diversos medios y se reconvierte en una figura de ficción de referencia en la mente colectiva.
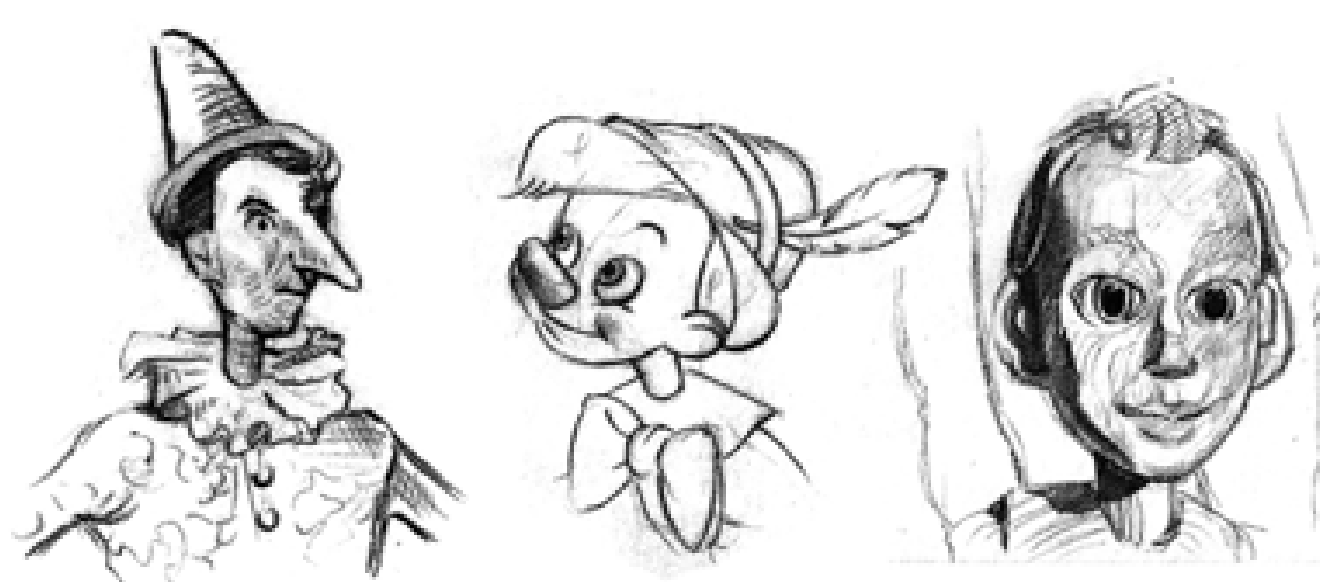

Figuras 7, 8 y 9 . Estudio de tres versiones diferenciadas de Pinocho. Según Enrico Mazzanti, la factoría de Walt Disney y la pelicula de Imagen real de 1996. Vicente Perpiña Giner, 2015

\section{Pinocho. Otro cuentista ilustre.}

Podremos establecer un perfecto símil con la figura creada por el periodista satírico y escritor Carlo Collodi (Carlo Lorenzini, Florencia, 1826 -1890) para su célebre obra Las aventuras de Pinocho (Le aventure di Pinocchio. Storia di un buratino) publicado de forma seriada entre 1881 y 1883 en la publicación periódica dirigida a la infancia Giornali per i bambini, y basado, retomando nuestra premisa, en una antigua leyenda toscana. Justo un mes después de su finalización periódica, aparecerá recopilado en un volumen ilustrado por Enrico Mazzanti, cuya aproximación al personaje descrito por Collodi representa a un espigado títere, de estructura sencilla (fig. 7). Más repercusión tuvo incluso la versión gráfica de Attilio Musino para la edición de 1911.

Evidentemente Pinocho tenía las trazas para convertirse rápidamente en un arquetipo mítico complejo y polivalente.

Es inevitable ver en el texto original una voluntad moral y pedagógica al respecto de la indisciplina del protagonista, en ocasiones narración deudora de la picaresca y en otras, cuento de hadas. Todo ello apoyado en la barrera moral que supone mentir, representado por el símbolo de que al hacerlo nos crezca la nariz, es decir, que se haga evidente en quien nos observa por los gestos involuntarios que podemos llegar a mostrar sin darnos cuenta.

Los embustes, en tanto que cuentos, sientan una base comparativa entre Pinocho y Münchhausen y evidencian la lucha de la razón contra la fantasía y la mentira y la transgresión de la virtud como actos humanos.

Por otro lado, está la otra fundamentación de la novela, el que un objeto inanimado sea dotado de vida. Recurso que se ha utilizado en numerosos relatos, incluso en el Génesis del Antiguo Testamento, en el que el hombre cobra vida a partir de un pedazo de barro. E incluso podríamos fundamentarlo en el concepto del homúnculo de la cultura alquímica que proviene de épocas más primitivas, representando el afán del hombre como creador, padre, figura que representa Geppeto al tallar al títere, y las ansias de comprender y explicar la creación. La 


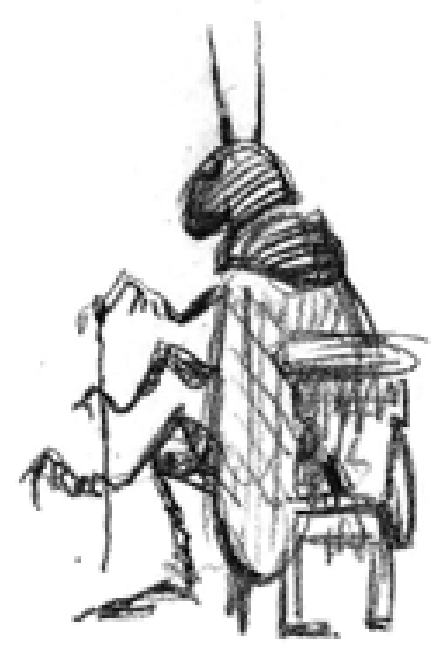

fig. 10

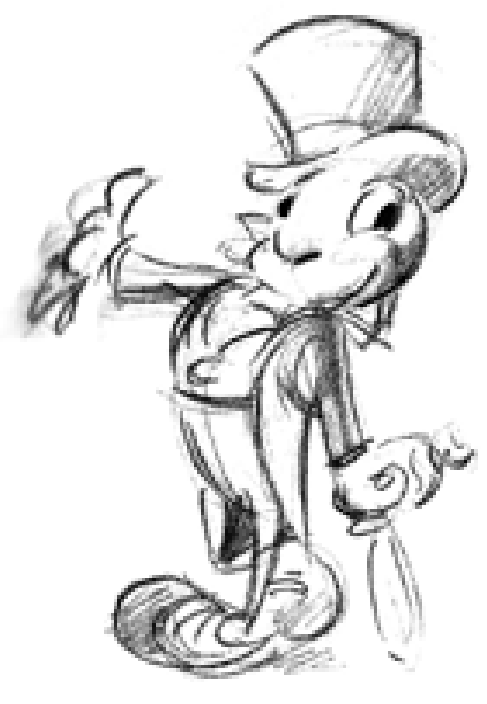

fig. 11
Figuras 10 y 11. Estudio de El Grillo Parlante, según Mazzanti y según 2015. función de madre la cumple el Hada de cabellos Turquesa. Aunque Pinocho la conoce cuando aún es pequeña, al no envejecer éste, más tarde cumplirá el papel de progenitora y más, al convertirlo durante su sueño en un niño de verdad.

Reconocemos a Pinocho como a una marioneta de madera dotada de vida al que le crece la nariz al mentir, pero si buscamos mentalmente una imagen, sin duda, a la gran mayoría, nos sobrevendrá el candoroso diseño de la factoría Walt Disney (fig. 8) de 1940. Sin embargo, aunque no fue ésta la primera representación gráfica que se nos ofreció, sí fue la de mayor calado, dado el poder de divulgación de la cinematografía sumado al de una gran empresa y las miles de reproducciones y adaptaciones de la misma bajo el mismo sello en una gran variedad de productos derivados. Esta adaptación tiene una serie de diferencias sustanciales respecto a la original, y son las que hemos acogido en nuestra memoria global. Geppeto juega aún más el papel de padre, y podemos establecer un nexo religioso, al rezar éste por la noche para que su creación sea un niño de verdad, por obra del Hada, aquí llamada Azul. Al igual que Münchhausen y sus criados en sus aventuras marinas, Pinocho y Geppeto son engullidos por una enorme ballena, cuyo interior podemos entender como una posible representación del purgatorio, y tras la estancia en el mismo y su coqueteo con la muerte se erigirá resurrecto y convertido en una persona real. Al igual que el barón alemán pudo vencer al Gran Turco tras salir con fuerzas renovadas del estómago de un gran pez con la ayuda de un poco de rapé espolvoreado y un estornudo acuático de tamañas dimensiones. $\overline{\text { Vicente Perpiñá Giner }}$

En 2009 se licencia en Bellas Artes en la Universitat Politècnica de Valencia, donde se especializará (n) En 2011 termina el Máster de Producción Artística, tras el cua obtiene la Beca DKV Grand Tour que le concede la oportunidad de disfrutar una estancia en la ciudad de Nueva York.

Es Profesor de Secundaria por la Universitat de València. Ha editado anzines y colaborado en distintas publicaciones gráficas Actualmente cursa el Programa investigación, en el cual realiza el estudio del proceso histórico y morfológico que sufren los cuentos populares hasta transformarse en peliculas animadas y su influencia en el imaginario colectivo. Su obra ha sido expuesta en Valena

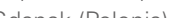

\section{Bibliografía}

BÜRGER, GÖTTFRIED AUGUST: Las aventuras del Barón de Münchhausen, Madrid, Alianza, 2003. AVO. Viaje por España 1, Madrid Grech, 1988.

GUBERN, ROMÁN: Máscaras de ficción, Barcelona, Anagrama, 2002 PERRAULT, CHARLES: Contes de Perrault, París, Hachette, 1993. PROPP, VLADIMIR: Las raíces históricas del cuento, Madrid, Fundamentos, 2008. SALMERÓN INFANTE, MIGUEL: "El lado oscuro de los cuentos de belleza, 1,2012.
Otro personaje que cobró una importancia fundamental, sobre todo a partir de la adaptación animada de Walt Disney fue Pepito Grillo (Jiminy Cricket en su versión original anglosajona), quien representaba la conciencia de la que carecía el muñeco, y era a la vez su superego. De El Grillo Parlante que cabe en una silla en la versión de Collodi y Mazzanti (fig. 10) y sirve de guía en los momentos en que Pinocho trata de transgredir ciertos comportamientos morales, al agradable grillo antropomórfico, de aspecto prácticamente humano, simpático y burgués, que genera mayor empatía con el espectador. Diseñado éste por Ward Kimball para los estudios Disney (fig.11). Aquí podemos observar de forma evidente el cambio de realidad entre la sociedad de finales del siglo XIX y mediados del XX, tanto en la concepción del personaje, como en la función de su apariencia estética.

Muchas adaptaciones han ido surgiendo, sobre todo, en el medio cinematográfico, como la premiada película de imagen real Pinocchio de 1971 dirigida por Luigi Comencini e interpretada por Nino Manfred en el papel de Geppeto y Gina Lollobrigida como el Hada Azul en la que el muñeco cobra vida la primera noche de su existencia dotando de mayor realismo a la cinta; la coproducción entre Alemania, Inglaterra y Francia Pinocho, la leyenda (The Adventures of Pinocchio) de 1996, también de imagen real y con Martin Landau como Geppeto en la que Pinocho (fig. 9) y el grillo eran muñecos animatrónicos; o la reconstrucción que se hace del mito en Inteligencia Artificial (A.I. 2001) dirigida por Steven Spielberg, de la que Stanley Kubrick sentó las bases antes de fallecer, y que podemos tomar como un cuento maravilloso situado en un futuro no muy lejano, en la que vemos como la robótica ha llegado a poder crear un niño capaz de tener sentimientos. Mostrando así, la problemática entre los avances científicos y la progresión moral como especie.

\section{Colorín colorado... A modo de conclusión.}

Retomamos a Román Gubern haciendo referencia a la longevidad de los mitos:

"Las protofantasias perduran a lo largo de los siglos bajo diferentes ropajes, que los acomodan a su tiempo, y se entremezclan a veces con otras.n"

Para poder concluir que, la longitud y extensión de estos constructos va más allá del contexto en el que fueron creados, incluso trascendiendo y adaptándose a distintas culturas, siendo construcciones folclóricas no sólo de un pueblo concreto sino de un colectivo mayor. Se generan versiones, sujetas a su tiempo y lugar, al medio o soporte o a su desarrollo previsiblemente longevo. Así los mitos pueden transgredirse, cambiarse y retorcerse pero no se pueden trascender. Parten y desembocan en ejemplos de realidad para que los medios de codificación sujetos a nuestros sentidos y al lenguaje hagan que ellos viajen con nosotros y nos acompañen. 